\title{
Cardiac tumors in children: A 20-year review of clinical presentation, diagnostics and treatment
}

\author{
Joanna Kwiatkowska ${ }^{1, A, D, E}$, Anna Wałdoch ${ }^{1, C, E}$, Jarosław Meyer-Szary ${ }^{1, B}$, Piotr Potaż ${ }^{1, B, C}$, Marek Grzybiak ${ }^{2, E, F}$ \\ ${ }^{1}$ Department of Pediatric Cardiology and Congenital Heart Defects, Medical University of Gdańsk, Poland \\ 2 Department of Clinical Anatomy, Medical University of Gdańsk, Poland \\ A - research concept and design; $\mathrm{B}$ - collection and/or assembly of data; C - data analysis and interpretation; \\ $D$ - writing the article; $E$ - critical revision of the article; $F$ - final approval of article
}

Address for correspondence

Joanna Kwiatkowska

E-mail: joannak@gumed.edu.pl

Funding sources

none declared

Conflict of interest

none declared

Received on August 31, 2015

Revised on January 20, 2016

Accepted on March 09, 2016

\author{
Abstract \\ Background. The use of new imaging techniques has contributed significantly to earlier diagnosis and \\ treatment of cardiac tumors.
}

Objectives. The aim of the study was to analyze data from children with cardiac tumors in terms of clinical presentation, the role of noninvasive diagnostic procedures and the long-term outcome.

Material and methods. The data analyzed retrospectively concerned 30 children in whom cardiac tumors were diagnosed from January 1995 to July 2015. The cardiac evaluation included a review of the subjects' medical records and medical history, a physical examination, standard 12-lead electrocardiography, echocardiography and 24-h Holter ECG monitoring at the time of diagnosis and at 6-12 month intervals during the follow-up at the authors' outpatient clinic.

Results. Most of the children did not need cardiac surgery; surgical tumor excision was necessary in 3 cases only. There was 1 death in the follow-up period. Rhabdomyoma was diagnosed in 22 cases, and in 16 of them tuberous sclerosis was confirmed during the follow-up period. In the remaining 8 cases, fibroma was the most likely diagnosis.

Conclusions. The symptomatology of cardiac tumors in children can vary greatly, from the absence of any symptoms up to heart failure and respiratory distress indicating the need for surgical intervention. The diagnosis of cardiac tumors relies almost exclusively on noninvasive imaging techniques. The observations in this study confirm the fact that the most common cardiac tumor in children is rhabdomyoma, which may disappear spontaneously. Most patients with cardiac tumors do not require treatment.

Key words: tumor, cardiac, pediatric, fetal

DOI

10.17219/acem/62121

Copyright

Copyright by Author(s)

This is an article distributed under the terms of the

Creative Commons Attribution Non-Commercial License

(http://creativecommons.org/licenses/by-nc-nd/4.0/) 
It is still difficult to estimate the incidence of cardiac tumors in the pediatric population. ${ }^{1-3}$ Most heart tumors are benign, and rhabdomyoma is the most common of them. ${ }^{1,2}$ Malignant and metastatic tumors have been described, but they are rare. Cardiac tumors are mainly manifested by murmurs, arrhythmias, cyanosis, respiratory distress, hemopericardium or exudative pericarditis and heart failure. ${ }^{1,2}$ The use of new imaging techniques has contributed significantly to earlier diagnosis and treatment. ${ }^{1-3}$

The aim of this study was to analyze data from children with cardiac tumors in terms of the clinical presentation, the role of noninvasive diagnostic procedures and the long-term outcome.

\section{Material and methods}

The data analyzed retrospectively concerned 30 children in whom cardiac tumors were diagnosed from January 1995 to July 2015 (Table 1) at the authors' clinic. The cardiac evaluation included a review of the subjects' medical records and medical history, a physical examination, standard 12-lead electrocardiography, echocardiography and 24-h Holter ECG monitoring at the time of diagnosis and at 6-12 month intervals during the follow-up period. As there is no uniform heart failure functional classification for children, the present authors decided to use the Ross classification (or a modification thereof) for children below 14 years of age and the New York Heart Association (NYHA) functional classification for children aged 14 or over.

From 1995 to 2005, echocardiography was the only noninvasive imaging tool available at the clinic. Since 2005 cardiac computed tomography (CT) has also been available, since 2010 magnetic resonance imaging (MRI) as well.

Because of the great progress in prenatal diagnosis, since 2007 it has been possible to diagnose children with

Table 1. Characteristics of the study group of 30 children with cardiac tumors

\begin{tabular}{|lc|}
\hline Study group, $\mathrm{n}$ & 30 \\
Female/male, $\mathrm{n}(\%)$ & $17(57 \%) / 13(43 \%)$ \\
Age at diagnosis, median (range) & 44 days, (1 day to \\
& 16 years) \\
Family history of TSC, $\mathrm{n}(\%)$ & $3(10 \%)$ \\
Prenatal diagnosis, $\mathrm{n}(\%)$ & $3(10 \%)$ \\
Cardiac symptoms at the time of diagnosis, $\mathrm{n}(\%)$ & $25(83 \%)$ \\
Rhabdomyoma diagnosed on the basis of echo & $22(73 \%)$ \\
exam, $\mathrm{n}(\%)$ & $8(27 \%)$ \\
Fibroma suspected, $\mathrm{n}(\%)$ & $8(27 \%)$ \\
CT/MRI, $\mathrm{n}(\%)$ & $30(100 \%)$ \\
\hline Neurological consultation, $\mathrm{n}(\%)$ & \\
\hline
\end{tabular}

$\mathrm{n}$ - number of children; TSC - tuberous sclerosis. a positive family history of tuberous sclerosis (TSC) prenatally. At the authors' center, all children with TSC undergo a noninvasive cardiac investigation. The required medical and/or cardiosurgical management and outcomes were noted for all the children in the present study.

\section{Results}

The baseline characteristics of the study group are presented in Table 1 . There were 30 children, 17 females (57\%) and 13 males (43\%). Their ages ranged from 1 day to 16 years (median: 44 days) at the time of diagnosis.

Table 2 shows the patients' clinical presentation at the time the cardiac tumors were diagnosed. A positive family history of TSC was present in 3 cases (10\%), and in all of them the diagnosis of TSC was made prenatally and confirmed postnatally.

Table 2. Clinical symptoms and signs at diagnosis

\begin{tabular}{|lc|}
\hline Study group, $\mathrm{n}$ & 30 \\
Family history of TSC, $\mathrm{n}(\%)$ & $3(10 \%)$ \\
Heart failure, $\mathrm{n}(\%)$ & $3(10 \%)$ \\
Heart murmur, $\mathrm{n}(\%)$ & $15(50 \%)$ \\
Arrhythmias and conduction abnormalities, n (\%) & $7(23 \%)$ \\
No cardiac symptoms, $\mathrm{n}(\%)$ & $5(17 \%)$ \\
\hline
\end{tabular}

$\mathrm{n}$ - number of children; TSC - tuberous sclerosis.

Five neonates $(17 \%)$ were diagnosed immediately postpartum - 3 were referred due to the presence of a heart murmur and 2 because of an irregular heart rate.

In 3 other cases (10\%), respiratory distress and heart failure with low cardiac output were the reasons for the cardiac consultation.

Other signs of cardiac tumors in the study group were heart murmurs in 15 cases (50\%) and various forms of arrhythmia in 7 cases (23\%). There were 5 children (17\%) who did not manifest any cardiac symptoms. They had already undergone a cardiac investigation due to a clinical picture of tuberous sclerosis in 3, for a sport eligibility qualification in 1 , and because of the prolongation of an upper respiratory tract infection in 1.

Electrocardiograms and 24-h Holter ECG monitoring showed abnormalities and a variety of arrhythmias in 7 children at the time of diagnosis. Nonspecific ST-T changes were present in 3 cases and aberrant intraventricular conduction in 2 cases. Coexisting right and left ventricular hypertrophy and right atrial enlargement were noted in 3 other cases. Tachycardia was discovered in 3 cases and bradycardia in 2 others (in 1 case with a prolonged PR interval). Six children had more than 1 abnormality at the time of diagnosis. 


\section{Images}

Echocardiography was the primary imaging method used in all patients (Figs. 1-4). Rhabdomyoma (Figs. 1a, $1 \mathrm{c}, 1 \mathrm{e}, 1 \mathrm{f})$ was diagnosed in 22 cases; in 16 of them tuberous sclerosis was confirmed during the follow-up period. All 16 patients who had confirmed TSC showed multiple rhabdomyomas on echocardiography. The size of the tumors ranged from $4 \mathrm{~mm}$ to $3 \mathrm{~cm}$.
Recently, computed tomography scanning and magnetic resonance imaging have been carried out in selected cases. The indications for scanning were a suspicion of tumor infiltration (MRI in 2 cases - Figs. 2c-d), difficulties in determining the tumor morphology and its boundaries by echocardiography (MRI in 3 cases and CT in 3 others). In the remaining 8 cases, fibroma was the most likely diagnosis based on echo and MRI examinations (Figs. 2a-d, 3a-b).

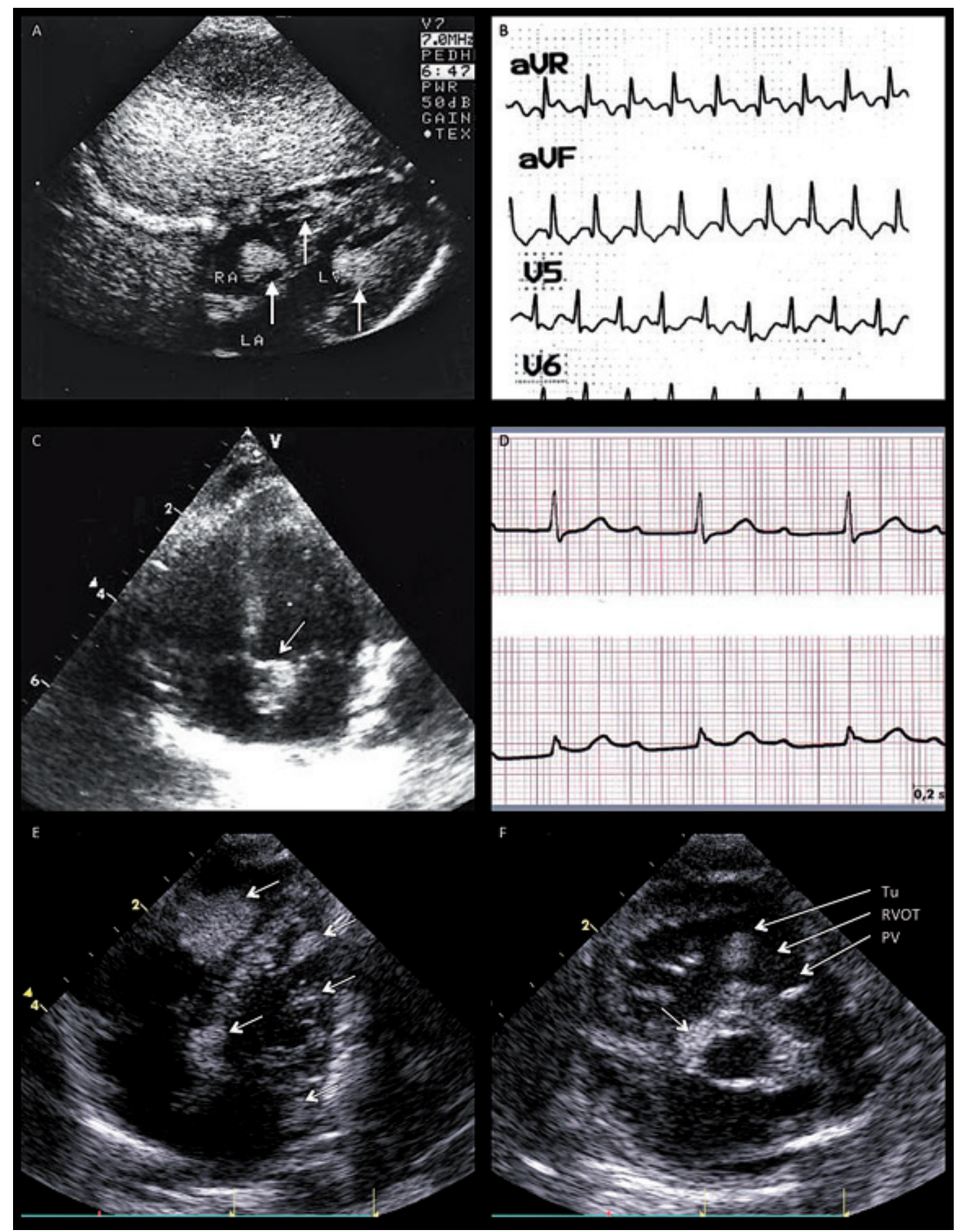

Fig. 1. Main features of cardiac tumors in children

Fig. 1a. Cardiac rhabdomyomas in an infant

Fig. 1b. Surface electrocardiogram, showing supraventricle tachycardia.

Further diagnostic procedures revealed Wolff-ParkinsonWhite syndrome. Transthoracic echocardiography in a modified 4-chamber view revealed round echogenic masses (arrows) bulging into the cavity of the left and right ventricles. The infant was found to have tuberous sclerosis

Fig. 1c-d. Transthoracic echocardiography in a 4-chamber view (c) in a 2-month-old girl, performed because of first degree atrioventricular block (d). A pathological mass is seen in the left atrium (arrow)

Fig. 1e-f. Cardiac rhabdomyomas. Neonatal echocardiography in a 4-chamber view (e) and in a short-axis view (f) showing multiple homogenous left and right ventricular cavity masses (arrows) 

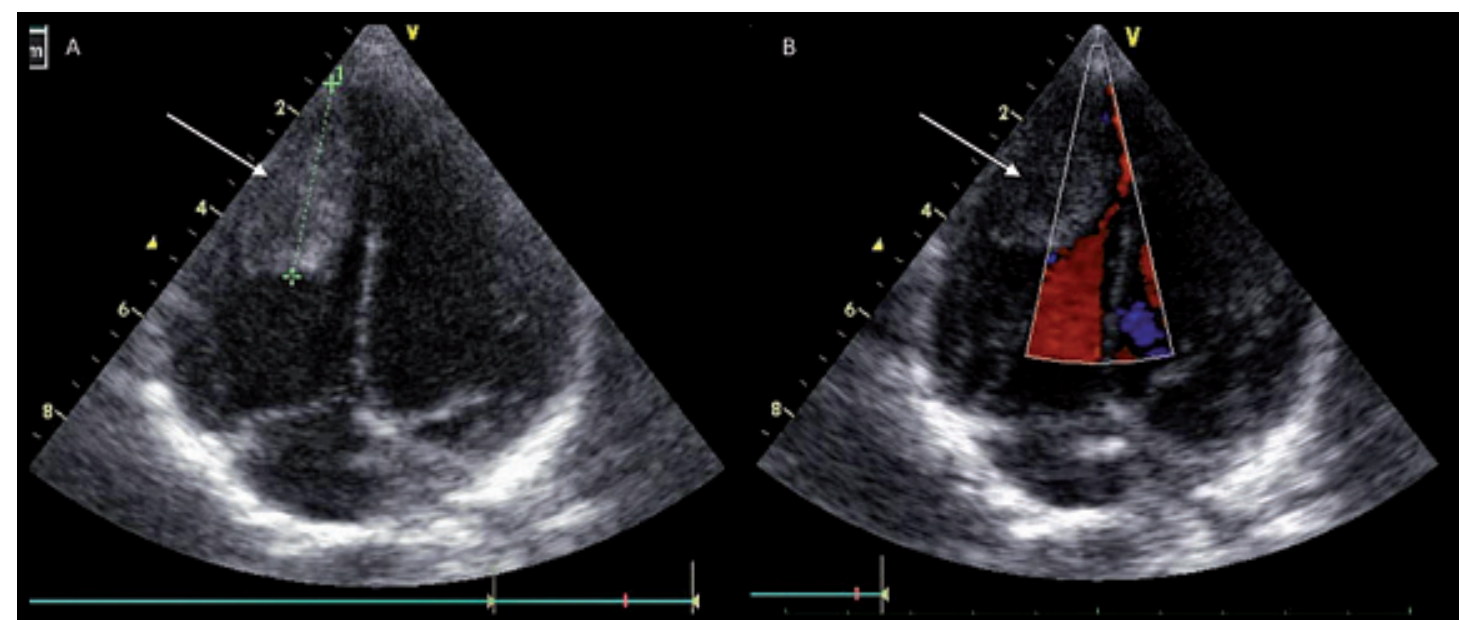

Fig. 2a-b. Transthoracic echocardiography of a child at the age of 2 years showing a right ventricular tumor

Fig. 2c-d. Cardiac magnetic resonance image showing a fibroma in the right ventricle
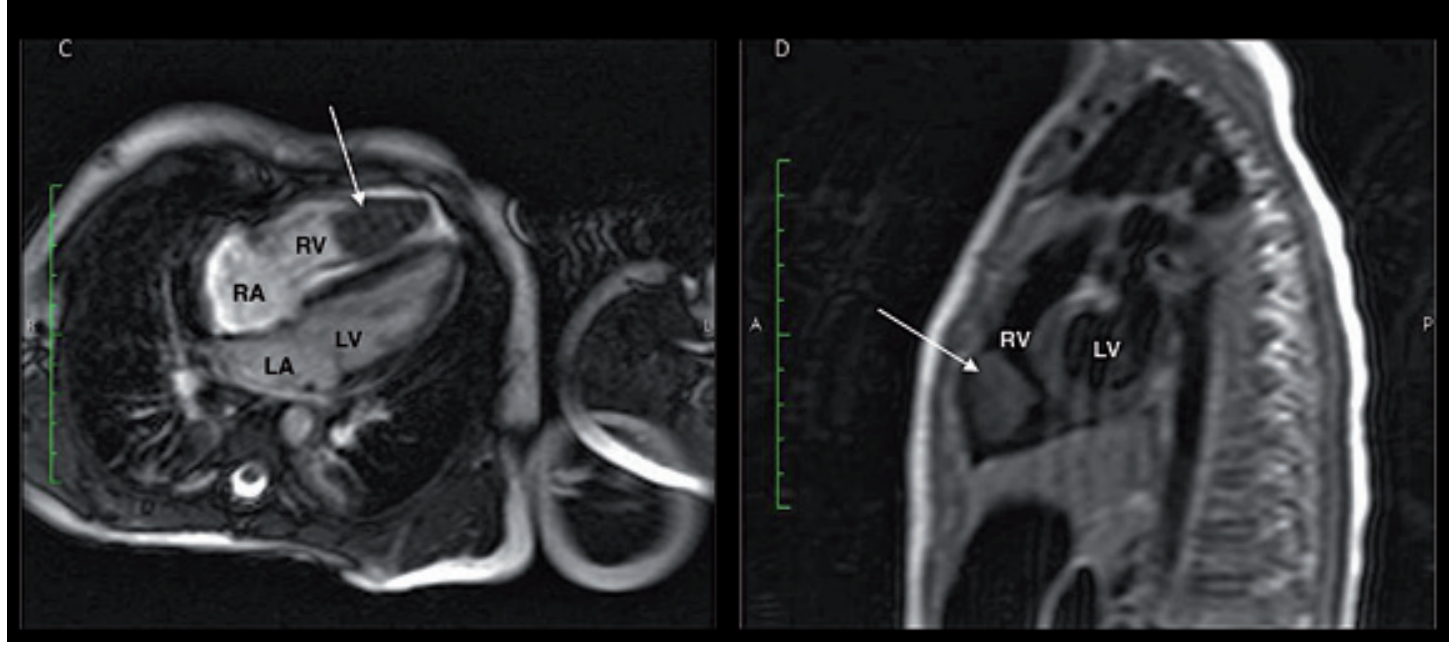

\section{Management and outcomes}

Table 3 presents the treatment regimens and outcomes in the study group.

Three infants (10\%) were severely hemodynamically compromised and required cardiac surgery. In 2 of them the left ventricle outflow tract was obstructed by the tumor, and in the third both left and right outflow tracts were obstructed by multiple rhabdomyomas. In these 3 cases subtotal tumor excision was performed. This enabled histological evaluations, which confirmed the presence of rhabdomyomas.

Table 3. Treatment regimens and outcomes

\begin{tabular}{|lc|}
\hline Study group, n & 30 \\
No medical/cardiosurgical management, n (\%) & $22(73 \%)$ \\
Surgery < age 1 year, n (\%) & $3(10 \%)$ \\
Surgery > age 1 year, n (\%) & $0(0 \%)$ \\
Reoperation, n (\%) & $0(0 \%)$ \\
Number of children treated with antiarrhythmic & $4(13 \%)$ \\
drugs, n (\%) & $12(40 \%)$ \\
Spontaneuos resolution of the tumor, n (\%) & $1(3 \%)$ \\
\hline Death, n (\%) & \\
\hline
\end{tabular}

n- number of children.
Three neonates and 1 other infant with various forms of arrhythmias (due to supraventricular re-entry tachycardia in 3 of them and focal atrial tachycardia in 1 case) were successfully treated for their symptoms with several antiarrhythmic drugs, applied according to standard guidelines.

Overall rhythm abnormalities were noted in 10 patients during the follow-up period: 2 had premature ventricular beats (Figs. 3c-f), 3 had supraventricular premature beats, 1 had ectopic atrial tachycardia, 3 had supraventricular re-entry tachycardia (Fig. 1b) and 1 had first degree atrioventricular block (Fig. 1d). The rest of the children had no documented arrhythmias.

\section{Follow-up results}

Table 4 presents the follow-up results. As of August 2015, 29 of the patients (97\%) were alive. There was 1 noncardiac death: A patient with TSC and cardiac rhabdomyomas without the need for surgical intervention who died suddenly at home at the age of 7 years. The child was severely mentally handicapped; at the parents' request, no autopsy was conducted.

At the last follow-up visit, 4 of the children were in functional class I according to the Ross classification 


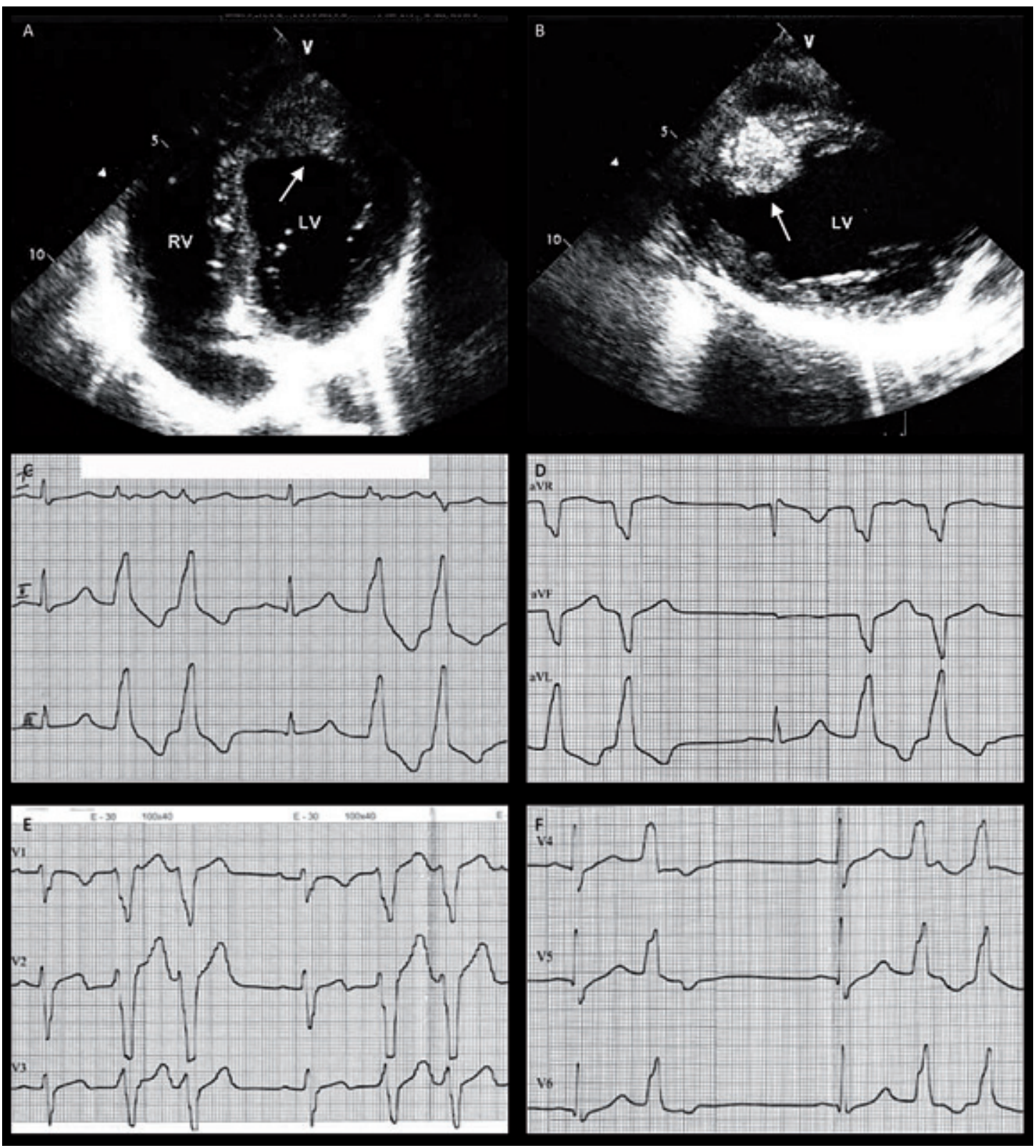

Fig. 3a-b. Transthoracic echocardiography in a modified 4-chamber view and in the parasternal long-axis view, performed in a teenage athlete due to ventricular ectopies revealed in surface electrocardiogram (3c-f). A pathological mass is visible in the apex of the left ventricle (arrow). Cardiac magnetic resonance image confirmed a fibroma in the left ventricle

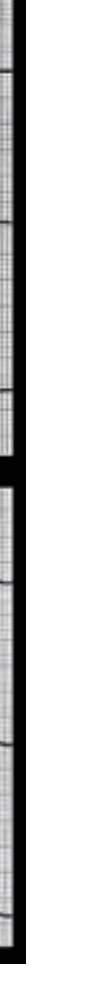

Table 4. Follow-up data at last cardiac evaluation

\begin{tabular}{|lc|}
\hline Alive, n (\%) & $29(97 \%)$ \\
NYHA I & $25 / 25$ \\
Ross (or modified Ross) I & $4 / 4$ \\
Arrhythmias and conduction disturbances, n (\%) & \\
VPB & $2(7 \%)$ \\
SVPB & $3(10 \%)$ \\
AET & $1(3 \%)$ \\
AVRT & $3(10 \%)$ \\
AVB I & $1(3 \%)$ \\
TSC confirmation and neurological follow-up, & $16(55 \%)$ \\
$n(\%)$ & \\
\hline
\end{tabular}

VPB - ventricular premature beat; SVPB - supraventricular premature beat; AET - atrial ectopic tachycardia; AVRT - atrioventricular reentry tachycardia; AVB I - first degree atrioventricular block. (or modification thereof), and 25 were in the NYHA functional class I.

Spontaneous resolution of the cardiac tumor occurred in 12 of the 16 children with a confirmed diagnosis of tuberous sclerosis. The mean time for the resolution of rhabdomyomas was 4 years, based on serial echo examinations (Fig. 4). In the rest of the study group, there was no progression on echo or MRI visualization, and no further indication for cardiac surgery. During observation periods of up to 20 years, none of the patients required a reoperation. Cardiac pharmacotherapy was not required by 22 children in the study group (73\%). 


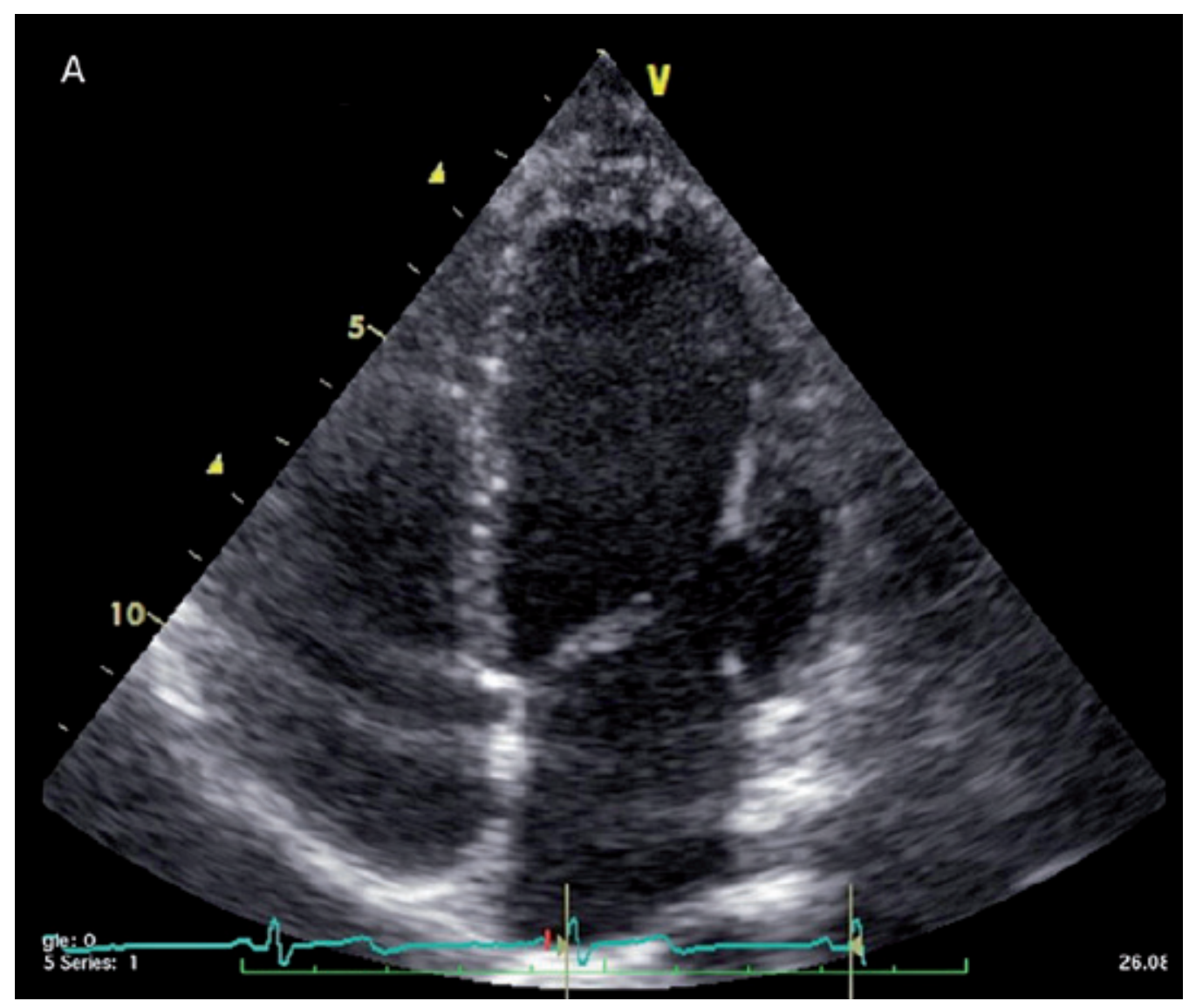

Fig. 4. Transthoracic echocardiography (4-chamber view) of a child with a confirmed diagnosis of tuberous sclerosis. Regression of rhabdomyomas after 4 years of follow-up

\section{Discussion}

\section{Tumor incidence}

Primary cardiac tumors are found in approximately 1 in $10000(0.01 \%)$ of routine post-mortem examinations of patients of all ages. ${ }^{4-7}$ Simcha et al. found an incidence of $8 / 10000(0.08 \%)$ in infants and children. ${ }^{8}$ Between 1950 1970 they diagnosed primary cardiac tumors in 8 children based on data from clinical symptoms, electrocardiography, angiocardiography and in only 2 cases were tumors found during the autopsy. Although cardiac tumors are uncommon, the number of cardiac lesions detected annually has increased significantly during recent decades, due to improved imaging techniques. ${ }^{9}$ During the 20 years from 1995 to 2015 the present authors diagnosed 30 cases of cardiac tumors in children at the Medical University of Gdańsk Department of Pediatric Cardiology and Congenital Heart Defects.

\section{Clinical presentation and required management}

In the present study group, nonspecific heart murmurs (in 15 out of 30 children) and arrhythmias (in 7 out of 30 children) were the most frequent symptoms leading to cardiac consultations. This coincides with other authors' observations. ${ }^{1,2,10,11}$ However, it should be emphasized that after birth, patients may not present obvious clinical findings, despite an extensive cardiac involvement.

In cases of newborns and infants with large rhabdomyomas who are critically symptomatic, presenting respiratory distress and congestive heart failure, cardiac surgery is required. ${ }^{12-14}$ In the present study group 3 infants (10\%) required cardiac surgery due to severe hemodynamic disturbances. Thomas-de-Montprevillea et al. presented almost 20 years of surgical experience with 59 patients (both adults and children), and one of their conclusions was that "there is a group of heart tumors requiring surgery mainly because of the mass effect". 15 Burke and Virmani reviewed the literature concerning heart tumors in children, and with regards to rhabdomyomas they concluded: "Due to a natural history of spontaneous regression of rhabdomyomas many patients are followed without surgery. However, serious symptoms may precipitate the need for surgical resection". 10

As Moradian et al. wrote: "Sudden death has been attributed to arrhythmias in pediatric patients of all ages. These arrhythmias may be a result of either severe hemodynamic compromise or contiguous location of tumors to the conduction system"16; another reported cause is ectopic tachyarrhythmia caused by a tumor. ${ }^{12}$ In the literature, all common rhythm disturbances have been reported. ${ }^{10,13,16-19}$ In a review of 224 fetuses and neonates with cardiac tumors collected from the literature, Isaacs ${ }^{12}$ 
confirmed the observations of Moradian et al. ${ }^{16}$ and his conclusions were similar to the present authors'

While it is well established that cardiac rhabdomyomas are often the only manifestation of $\mathrm{TSC}^{2,12,13,20}$, it is difficult to estimate the true incidence of rhabdomyomas, as this tumor often regresses over time. The published data suggest that in $30 \%$ to $91 \%$ of cases, cardiac rhabdomyomas are associated with TSC. ${ }^{2,21}$ In a study by Beghetti et al. $41 \%$ of cardiac rhabdomyomas cases were associated with $\mathrm{TSC}^{2}$, in contrast to the data reported by Holley et al., who stated that the incidence was $91 \% .{ }^{21}$ Despite the considerable discrepancies in the frequency of coexisting rhabdomyiomas and TSC, both Beghetti et al. and Holley et al. emphasize that the seizures were a leading symptom of TSC. In tuberous sclerosis it is not the cardiac manifestations but rather the cerebral ones that are crucial to the prognosis. ${ }^{13,18}$ In the present study all the children with cardiac tumors underwent neurological consultations, and all the children with TSC have been under regular neurological supervision.

\section{Diagnosis}

Lately the diagnosis for most patients with cardiac tumors is established before they are one year old, or even prenatally. ${ }^{12,18}$ Verhaaren et al. reported 87 cases with a prenatal diagnosis of rhabdomyoma. ${ }^{22}$

As Moradian et al. wrote: "Fetal cardiac rhabdomyomas, albeit rare, are the most common fetal cardiac tumors. More than $60 \%$ of prenatally detected cardiac tumors are rhabdomyomas, and these are often associated with tuberous sclerosis".16

In most cases it is not easy to obtain a cardiac tumor biopsy, either by percutaneous or catheter biopsy; therefore, imaging plays a central role in the evaluation of cardiac tumors. ${ }^{3,23}$ The primary imaging modality is echocardiography, but in doubtful cases other imaging modalities are employed to enhance visualization. Other centers confirm that MRI is an important tool in the evaluation of cardiac neoplasms, helping to accurately predict the type of cardiac tumor and establish a treatment strategy. ${ }^{3,24,25,26}$

Data from the literature and the results of the present study show that most primary cardiac tumors that occur in children and young people are benign neoplasms. 1,2,27,28,29,30 According to previous research, rhabdomyomas and fibromas are the most frequently occurring cardiac tumors in children. ${ }^{1,2}$ The present authors' long-term observations support this statement.

The clinical presentation of cardiac tumors, along with morphologic findings obtained from echocardiography with additional CT and MRI in selected cases, now gives enough information for the identification of different tumor types. The scope and need for future multicenter research in this field should be considered.

\section{Spontaneous tumor regression}

Beghetti et al. ${ }^{2}$ reported partial or complete spontaneous regression in $54 \%$ of 44 analyzed patients. In the present study, spontaneous resolution of the tumor occurred in 12 out of 16 children with a confirmed diagnosis of tuberous sclerosis (75\%) in a mean time of 4 years, based on repeated echo examinations. In the rest of the study group there was no progression on echo and/or MRI visualization, and no further indication for a cardiac surgery.

\section{Conclusions}

The symptomatology of cardiac tumors in children can vary greatly: from the absence of any symptoms to a heart failure and respiratory distress requiring surgical intervention. Due to the individual course of the disease, all patients, even asymptomatic ones, require regular cardiac follow-ups, including imaging and electrocardiographic procedures. Currently, the diagnosis of cardiac tumors relies almost exclusively on noninvasive imaging techniques: echocardiography, CT and/or MRI. The authors' observations confirm the fact that the most common cardiac tumor in children is rhabdomyoma, which may disappear spontaneously in the majority of patients over the long term. Most patients with cardiac tumors do not require treatment.

\section{Limitations}

As a retrospective study, the data collection was limited because of the long follow-up period. The available medical records were limited to those obtained as part of routine cardiac care at the authors' center.

\section{References}

1. Becker AE. Primary heart tumors in the pediatric age group: A review of salient pathologic features relevant for clinicians. Pediatr Cardiol. 2000;21:317-323.

2. Beghetti M, Gow RM, Haney I, Mawson J, Williams WG, Freedom RM. Pediatric primary benign cardiac tumors: A 15-year review. Am Heart J. 1997;134:1107-1114.

3. Hoey ETD, Shahid M, Ganeshan A, Baijal S, Simpson H, Watkin RW. MRI assessment of cardiac tumours: Part 1, multiparametric imaging protocols and spectrum of appearances of histologiacally benign lesions. Quant Imaging Med Surg. 2014;4:478-488.

4. Reynen K. Frequency of primary tumors of the heart. Am J Cardiol. 1996;77:107-116.

5. Uzun O, Wilson DG, Vujanic GM, Parsons JM, De Giovanni JV. Cardiac tumours in children. Orphanet $J$ Rare Dis. 2007;2:11-25.

6. Gunter T, Schreiber Ch, Noebaur Ch, Eicken A, Lange R. Treatment strategies for pediatric patients with primary cardiac and pericardial tumors: A 30-year review. Pediatr Cardiol. 2008;29:1071-1076.

7. Marx GR, Moran AM. Cardiac tumors. In: Allen HD, Driscoll DJ, Shaddy RE, Feltes TF, eds. Heart Disease in infants, children and adolescents including the fetus and young adults. $8^{\text {th }}$ ed. Moss and Adams', Lippincott Williams \& Wilkins;2013:1549-1564.

8. Simcha A, Wells BG, Tynan MJ, Waterston DJ. Primary cardiac tumours in childhood. Arch Dis Child. 1971;46:508-514. 
9. Gusman M, Servaes S, Feygin T, Degenhardt K, Epelman M. Multimodal imaging in the prenatal diagnosis of tuberous sclerosis complex. Case Rep Pediatr. 2012;925-646.

10. Burke A, Virmani R. Pediatric heart tumors. Cardiovascular Pathology. 2008;17:193-198.

11. Freedom RM, Lee KJ, MacDonald C, Taylor G. Selected aspects of cardiac tumors in infancy and childhood. Pediatr Cardiol. 2000;21: 299-316.

12. Isaacs H. Fetal and neonatal cardiac tumors. Pediatr Cardiol. 2004; 25:252-273.

13. Kwiatkowska J, Aleszewicz-Baranowska J, Komorowska W, Siebert J. Rodzinne występowanie choroby Bourneville'a-Pringle'a: opis przypadku. Fam Med Prim Care Rev. 2008;10:1212-1214.

14. Perdeus $P$, Werner B, Kaliciński Z. Cardiac tamponade in a neonate with cardiac tumour. Kardiol Pol. 2006;64:309-311.

15. Thomas-de-Montprevillea V, Nottinb R, Dulmeta E, Serrafc A. Heart tumors in children and adults: clinicopathological study of 59 patients from a surgical center. Cardiovascular Pathology. 2007; 16:22- 28.

16. Moradian M, Dalili M, Merajie M. Prenatal diagnosis of tuberous sclerosis by fetal echocardiography with an unusual clinical course after birth. Arch Cardiovasc Image. 2013;1:83-85.

17. Sallee D, Spector ML, van Heeckeren DW, Patel CR. Primary pediatric cardiac tumors: A 17-year experience. Cardiol Young. 1999;9:155-162.

18. Aleszewicz-Baranowska J, Potaż P, Kwiatkowska J, Ereciński J, Komorowska-Szczepańska W. Komorowe zaburzenia rytmu u młodego sportowca z guzem serca: koincydencja czy przyczyna? Fam Med Prim Care Rev. 2009;11:812-814.

19. Bang K, Kim YH, Kim CS, Lee SL, Kwon TC. Supraventricular tachycardia in neonate with cardiac rhabdomyoma and tuberous sclerosis. Korean J Pediatr. 2008; 51:766-770.
20. Bosi G, Lintermans JP, Pellegrino PA, Svaluto-Moreolo G, Vliers A. The natural history of cardiac rhabdomyoma with and without tuberous sclerosis. Acta Paediatr. 1996;85:928-931.

21. Holley DG, Martin GR, Brenner Jl, et al. Diagnosis and management of fetal cardiac tumors: A multicenter experience and review of published reports. J Am Coll Cardiol. 1995;26:516-20.

22. Verhaaren HA, Vanakker O, De Wolf D, Suys B, Francois K, Matthys $D$. Left ventricular outflow obstruction in rhabdomyoma of infancy: Meta-analysis of the literature. J Pediatr. 2003;143:258-263.

23. Kaminaga T, Takeshita $T$, Kimura I. Role of magnetic resonance imaging for evaluation of tumors in the cardiac region. Eur Radiol. 2003;13:L1-L10.

24. Beroukhim RS, Prakash A, Buechel ERV, et al. Characterization of cardiac tumors in children by cardiovascular magnetic resonanse imaging. JACC. 2011;10:1044-1054.

25. Sparrow PJ, Kurian JB, Jones TR, Sivananthan MU. MR Imaging of Cardiac Tumors. Radio Graphics. 2005;25:1255-1276.

26. Kiaffas MG, Powell AJ, Geva T. Magnetic resonance imaging evaluation of cardiac tumor characteristics in infants and children. Am J Cardiol. 2002; 89: 1229-1233.

27. Coard KCM. Primary tumors of the heart: Experience at the University Hospital of the West Indies. Cardiovascular Pathology. 2007;16: 98-103.

28. Yu K, Liu Y, Wang H, Hu S, Long C. Epidemiological and pathological characteristics of cardiac tumors: A clinical study of 242 cases. Interact Cardio Vasc Thorac Surg. 2007;6:636-639.

29. ElBardissi AV, Dearani JA, Daly RC, et al. Survival after resection of primary cardiac tumors. A 48-year experience. Circulation. 2008; 118(Suppl 1):S7-S15.

30. Kamiya $H$, Yasuda $T$, Nagamine $H$, et al. Surgical treatment of primary cardiac tumors 28 years' experience in Kanazawa University Hospital. Jpn Circ J. 2001;65:315-319. 